\title{
ITOPRIDE INCREASES EFFECTIVENESS OF THE MANAGEMENT OF THE OPIOID-INDUCED CONSTIPATION
}

\author{
Tomasz Dzierżanowski, Aleksandra Ciałkowska-Rysz \\ Palliative Medicine Laboratory, Oncology Chair, Medical University in Lodz, POLAND
}

\section{Abstract number: MSCC8-0968}

\section{Introduction}

Opioid-induced constipation (OIC) is difficult to manage, and the effectiveness of regular laxatives is poor. It is strongly recommended to routinely prescribe laxatives for the management or prophylaxis of opioid-induced constipation.[1] Adding prokinetics may increase the effectiveness of laxatives alone or opioid antagonists.[2] The intensity of the laxative treatment should be aimed to reach the bowel movements at least 3/week and to control the intensity of subjective symptoms.[3]

\section{Objectives}

To verify if itopride, added to laxatives or the opioid antagonist or the combination of both, increase the effectiveness of the management of opioid-induced constipation for comparisons.

\section{Methods}

The retrospective study was performed in adult palliative home-care patients with constipation and receiving strong opioids, and not treated with itopride before the observation. All patients received regular laxatives and additionally oxycodone/naloxone (ON group), itopride (I group), oxycodone/naloxone + itopride (ON+I group). The control group used laxatives only.

The primary measure was the improvement (decrease) of the necessity of laxative use in scale [0-4] assessed after 7 days of treatment. Kruskal-Wallis and Mann-Whitney U tests were used.

\section{Results}

56 out of 73 patients assessed met the inclusion criteria (female 43\%) analyzed in four groups: ON $(n=8)$, I $(n=$ $9), \mathrm{ON}+\mathrm{I}(\mathrm{n}=8)$, and Control $(\mathrm{n}=31)$. The aim of the laxative treatment was achieved in all groups with no statistical differences between groups. However, the necessity of laxatives decreased in groups where itopride was used, with statistical difference versus oxycodone/naloxone (I vs. ON p=0.007 and $\mathrm{ON}+\mathrm{I}$ vs. ON p=0.004) and

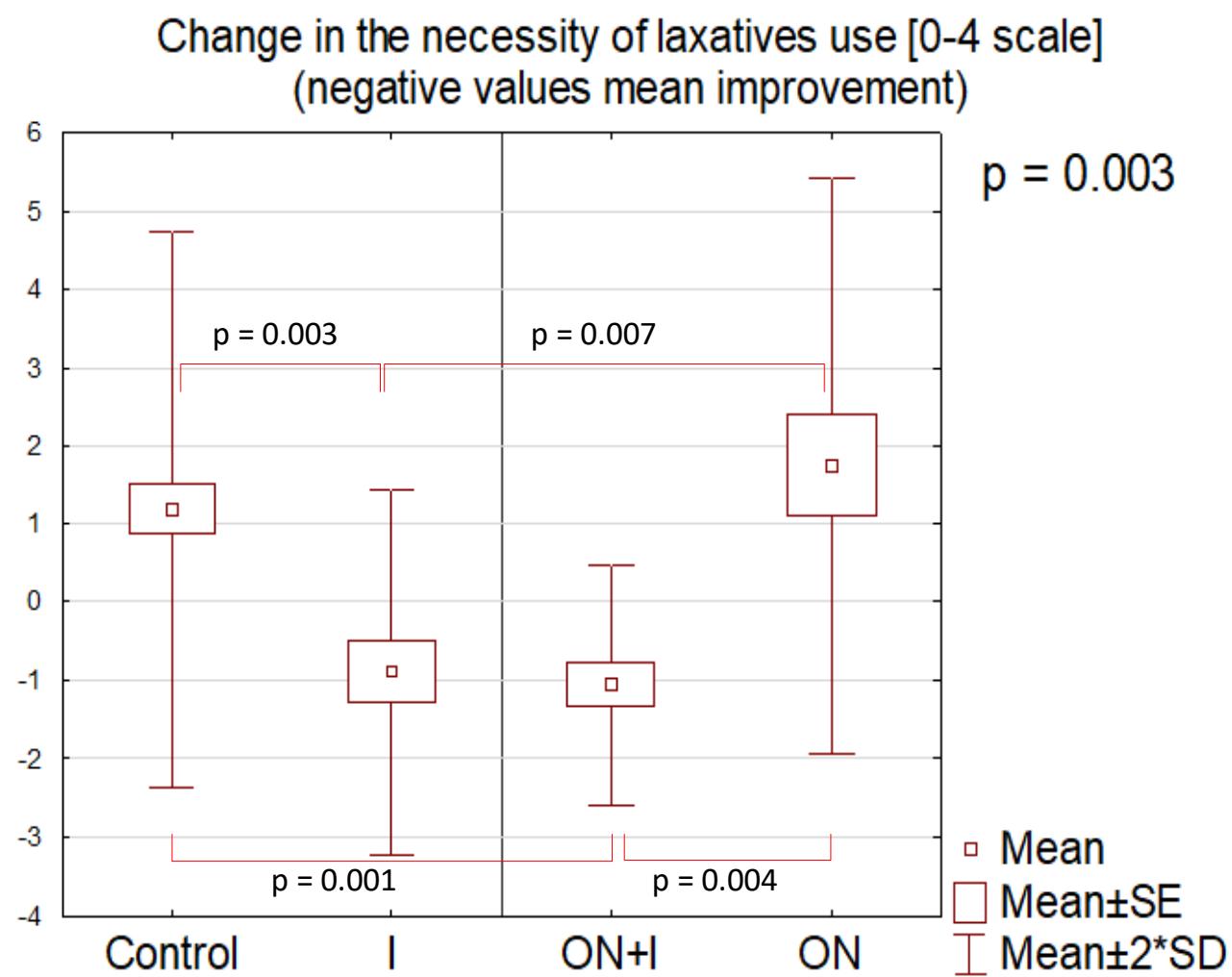
versus control group $(\mathrm{p}=0.003$ and $\mathrm{p}=0.001$ respectively).

There were no differences of laxatives use in patients taking oxycodone/naloxone and control.

Conclusions
All interventions appeared similarly effective in pre-
vention of constipation. However, adding itopride re-
sulted in a decrease of the necessity of the laxative use
in opioid-induced constipation patients, and seems to
be valuable in this often refractory condition.
Randomized control trial would be valuable to get
good quality evidence without systematic bias.

1. Caraceni A, Hanks G, Kaasa S, Bennett MI, Brunelli C, Cherny N, Dale O, De Conno F, Fallon M, Hanna M, Haugen DF, Juhl G, King S, Klepstad P, Laugsand EA, Maltoni M, Mercadante S, Nabal M, Pigni A, Radbruch L, Reid C, Sjogren P, Stone PC, Tassinari D, Zeppetella G. for the European Palliative Care Research Collaborative (EPCRC)on behalf of the European Association for Palliative Care (EAPC). Use of opioid analgesics in the treatment of cancer pain: evidencebased recommendations from the EAPC. Lancet Oncol. 2012 Feb;13 (2):e58-68.

2. Leppert W, Dzierżanowski T, Stachowiak A, Ciałkowska-Rysz A, Pyszkowska J. Constipation in cancer patients - the management recommendations of the Expert Group of the Polish Association for Palliative Medicine. Medycyna Paliatywna/Palliative Medicine. 2014;6(3):117-126.

3. Dzierżanowski T, Ciałkowska-Rysz A. <i>Assessment of the Usefulness of the Definition of Constipation in Palliative Care Patients according to Polish Society of Palliative Medicine 